\title{
NEOPLASIA MALIGNA DE TESTÍCULO: ANÁLISE EPIDEMIOLÓGICA DOS CASOS NOTIFICADOS NO BRASIL ENTRE 2015 E 2019
}

\section{ARTIGO ORIGINAL}

FACCO, Lucas 1, ALMENDRO, Lucas Pablo 2, MARQUES, Cristiane Peres 3, RIBEIRO, Edson Fábio Brito ${ }^{4}$, FECURY, Amanda Alves ${ }^{5}$, DENDASCK, Carla Viana 6, ARAÚJO, Maria Helena Mendonça de 7, OLIVEIRA, Euzébio de ${ }^{8}$, DIAS, Claudio Alberto Gellis de Mattos ${ }^{9}$

FACCO, Lucas. Et al. Neoplasia maligna de testículo: análise epidemiológica dos casos notificados no Brasil entre 2015 e 2019. Revista Científica

${ }^{1}$ Discente do Curso de Medicina da Universidade Federal do Amapá (UNIFAP).

${ }^{2}$ Discente do Curso de Medicina da Universidade Federal do Acre (UFAC).

${ }^{3}$ Discente do Curso de Engenharia de Produção da Universidade Federal de Mato Grosso do Sul (UFMS).

4 Discente do Curso de Medicina da Universidade Federal do Amapá (UNIFAP).

${ }^{5}$ Biomédica, Doutora em Doenças Tropicais, Professora e pesquisadora do Curso de Medicina da Universidade Federal do Amapá (UNIFAP).

${ }^{6}$ Teóloga, Doutora em Psicanálise, pesquisadora do Centro de Pesquisa e Estudos Avançados- CEPA.

${ }^{7}$ Médica, Mestra em Ensino e Ciências da Saúde, Professora e pesquisadora do Curso de Medicina do Campus Macapá, Universidade Federal do Amapá (UNIFAP). 8 Biólogo, Doutor em Doenças Tropicais, Professor e pesquisador do Curso de Educação Física, Universidade Federal do Pará (UFPA).

${ }^{9}$ Biólogo, Doutor em Teoria e Pesquisa do Comportamento, Professor e pesquisador do Programa de Pós-Graduação em Educação Profissional e Tecnológica (PROFEPT), Instituto Federal do Amapá (IFAP).

$\mathrm{RC}: 99646$

Disponível em: https://www.nucleodoconhecimento.com.br/saude/neoplasia 
Multidisciplinar Núcleo do Conhecimento. Ano. 06, Ed. 10, Vol. 07, pp. 62-74. Outubro de 2021. ISSN: 2448-0959, Link de acesso: https://www.nucleodoconhecimento.com.br/saude/neoplasia

\section{RESUMO}

A neoplasia testicular é uma patologia maligna relativamente incomum, representando $0,5 \%$ de todas as neoplasias masculinas, sendo mais frequente entre indivíduos de 15 a 34 anos. A apresentação clínica mais comum é massa testicular ou inchaço escrotal com ou sem dor ou trauma associados e o diagnóstico confirmatório padrão é a orquiectomia. Este trabalho teve como objetivo analisar epidemiologicamente os casos notificados de neoplasia maligna de testículo no Brasil entre os anos de 2015 e 2019. Os dados para a pesquisa epidemiológica foram obtidos no DATASUS e pesquisa bibliográfica foi realizada através de artigos científicos. A partir das informações reveladas nesta pesquisa, é possível observar um crescente aumento do diagnóstico de neoplasia maligna dos testículos no Brasil, com quase o dobro do número de casos observados entre os anos de 2015 e 2019. Apesar de relativamente incomum, o câncer de testículo é potencialmente mortal e sua gravidade não deve ser subestimada, devendo ser diagnosticado e tratado o mais precocemente possível. Possui elevada chance de cura, com tratamento cirúrgico definitivo, após diagnóstico confirmatório, na maioria dos casos, permitindo ao indivíduo acometido ter uma vida normal. Assim, mais estudos são necessários para revelar as razões do aumento de casos de câncer de testículo no Brasil e no mundo, para entender se as diferenças regionais estão relacionadas ao número de casos ou se é falha no diagnóstico e registro, bem como servirem de base para ações do poder público, no sentido de planejar e executar políticas dirigidas ao combate dos fatores desencadeantes dessa doença.

Palavras-chave: Neoplasias malignas, Tumores urológicos, Câncer de testículo, Orquiectomia inguinal, Epidemiologia.

$\mathrm{RC}: 99646$

Disponível em: https://www.nucleodoconhecimento.com.br/saude/neoplasia 


\section{INTRODUÇÃO}

O câncer ou neoplasia ocorre pela proliferação de células do organismo que apresentam modificações morfológicas e funcionais e que causam desordem nos tecidos. Tais alterações podem ter causas genéticas ou ambientais (Dias et al., 2017).

A neoplasia testicular é uma patologia maligna relativamente incomum, representando $0,5 \%$ de todas as neoplasias masculinas e $5 \%$ dos tumores urológicos (Rosen et al., 2011; Nci, 2021), e é mais frequente entre indivíduos de 15 a 34 anos (Baird et al., 2018). Além disso, a variante mais comum foi o tumor de células germinativas, com $95 \%$ dos casos, e o diagnóstico mais frequente nas massas palpáveis em estágio I clinicamente localizado (Adra e Einhorn, 2017; Pierorazio et al., 2018).

Foram apontados como fatores de risco para o desenvolvimento dessa tipologia de câncer: histórico prévio, com risco de 5 a $6 \%$ de sobrevir no testículo contralateral; histórico familiar, com risco de 8 a 10 vezes entre irmãos e 4 a 6 vezes entre filhos de um portador; criptorquidia, com odds ratio (OR) 4,3, intervalo de confiança de 95\% 3,6-5,1; orquidopexia (fixa testicular na bolsa escrotal) tardia , com OR de 5,8 se comparado com precoce; e síndrome de Klinefelter (Hemminki e Li, 2004; Walsh et al., 2007; Cook et al., 2010; Lip et al., 2012; Chan et al., 2014; Kier et al., 2016; Nery, 2019). A apresentação clínica mais comum é massa testicular ou inchaço escrotal com ou sem dor/trauma associado, tendo como diagnóstico diferencial orquite ou epididimite, pode então iniciar tratamento frusto com antibióticos (Nery, 2019). As metástases podem cursar, dependendo da localização, como: sintomas gastrointestinais; ginecomastia; cefaleia; lombalgia; massa em pescoço; sintomas respiratórios (dispneia, tosse e hemoptise) (Shaw, 2008). 
A metodologia diagnóstica para tal neoplasia começa durante o exame físico, com a palpação da bolsa escrotal, porém isso gera resultados ambíguos, então se faz o uso da investigação radiológica com a ultrassonografia transescrotal, a qual notouse o emprego crescente na detecção de lesões impalpáveis ou ambíguas (Dieckmann et al., 2013; Cheng et al., 2018). O diagnóstico confirmatório padrão é a orquiectomia (cirurgia para remover um ou ambos os testículos e todo o cordão espermático) radical, a qual possibilita estabelecer o caráter e muitas vezes já usada com tratamento (Ghoreifi e Djaladat, 2019). O tratamento padrão-ouro para massas testiculares com suspeita de malignidade, sem presença de sinais de metástases, foi estabelecido como a orquiectomia radical com remoção até nível do anel inguinal interno, sendo esta muitas vezes realizada durante um procedimento diagnóstico e ofertado a possibilidade de substituição por prótese testicular (Krege et al., 2008; Robinson et al., 2015; Ghoreifi e Djaladat, 2019). Ainda assim, utilizam-se os marcadores tumorais séricos (alfa-fetoproteína - AFP - e beta-gonadotrofina coriônica humana - Beta-HCG -) de maneira auxiliar para avaliar a efetividade do tratamento e aferir o prognóstico para o paciente, visto que devem ser estabelecidos antes e depois do tratamento, assim como no período de vigilância (Gilligan et al., 2019).

No contexto mundial, houve 72 mil diagnóstico e 9 mil mortes por ano para esse processo neoplásico, sendo que o risco de um homem desenvolver câncer testicular durante algum momento de sua vida foi estimado como 1 em cada 250 homens (Fitzmaurice et al., 2017; Acs, 2021). A projeção estimada para 2021 de novos casos de câncer testicular nos Estados Unidos da América foi de 9.470 diagnósticos e 440 óbitos, além de que se notou um uma maior frequência entre indivíduos brancos $(6,9$ indivíduos afetados por 100.000 homens) se comparado com os afro-americanos (1,2 indivíduos afetados por 100.000 homens) (Ghazarian et al., 2014; Acs, 2021).

Por sua vez, no âmbito nacional, notou-se certa escassez de dados epidemiológicos sobre tal neoplasia, porém constatou-se um aumento na mortalidade se comparado RC: 99646

Disponível em: https://www.nucleodoconhecimento.com.br/saude/neoplasia 
os dados de 2015 (359 óbitos, representado 0,05\% da mortalidade geral) e 2019 (446 óbitos, representado $0,06 \%$ da mortalidade geral) do Atlas de Mortalidade por Câncer - Sistema de Informações sobre Mortalidade (Nery, 2019; Inca, 2021).

\section{OBJETIVO}

Analisar epidemiologicamente os casos notificados de neoplasia maligna de testículo no Brasil entre os anos de 2015 e 2019.

\section{MÉTODO}

A pesquisa realizada utilizou metodologia qualiquantitativa (método misto), com dados governamentais, pois além dos dados numéricos envolveu a interpretação dos fenômenos (Facco et al., 2021).

A coleta foi realizada no banco de dados DATASUS (http://datasus.saude.gov.br/). Foram coletados dados nacionais de acordo com as seguintes etapas: A) Acessouse o link datasus.saude.gov.br, deslizou-se a seta com o mouse até a aba "Serviços em Destaque", logo após selecionou-se a opção "TABNET"; B) Na próxima página "TABNET" clicou-se na opção "Epidemiológicas e Morbidade" e por conseguinte selecionou-se a opção "Tempo até o início do tratamento oncológico - PAINEL oncologia". A partir daí, seguiram-se os passos: A) Na caixa "Linha", selecionou-se "Ano do diagnóstico" em todo o processo; B) Na caixa "Medidas", selecionou-se "Casos" em todo o processo; C) E na caixa "Coluna", selecionou-se os seguintes: "Estadiamento", "Faixa-Etária", "Modalidade Terapêutica", "Tempo do Tratamento", "UF da Residência", "UF do Diagnóstico" e "UF do Tratamento". Todos os dados coletados no sistema abrangem os períodos de 2015 a 2019. D) Na caixa de "seleção disponíveis" na opção "Diagnóstico", selecionou-se a opção "Neoplasias Malignas (Lei no 12.732/12) e em "Diagnostico detalhado" selecionou-se a opção "C62 Neoplasia Maligna dos testículos". Nas demais caixas de seleção disponíveis, 
mantiveram-se as opções padrão do sistema DATASUS. A compilação dos dados foi feita dentro do aplicativo Excel, componente do pacote Office da Microsoft Corporation, sendo que os dados das regiões do Brasil foram aglutinados a partir dos dados fornecidos por cada um dos Estados das devidas regiões. A pesquisa bibliográfica foi realizada em artigos científicos, utilizando-se para busca computadores pessoais dos autores do presente trabalho.

\section{RESULTADOS}

A Figura 1 denota o número de casos de neoplasia maligna dos testículos no Brasil entre os anos de 2015 e 2019, mediante o estadiamento. Nota-se que o estadiamento grau 3 foi o mais abrangente (789 casos), seguido pelo grau 1 (742), grau 2 (596), e 0 (141). Percebe-se que, na ampla maioria dos casos notificados, o critério de estadiamento foi classificado como "não se aplica", além de que 193 casos foram notificados como "ignorado". 
Figura 1 Mostra o número de casos de neoplasia maligna dos testículos no Brasil entre os anos de 2015 e 2019, mediante o estadiamento.

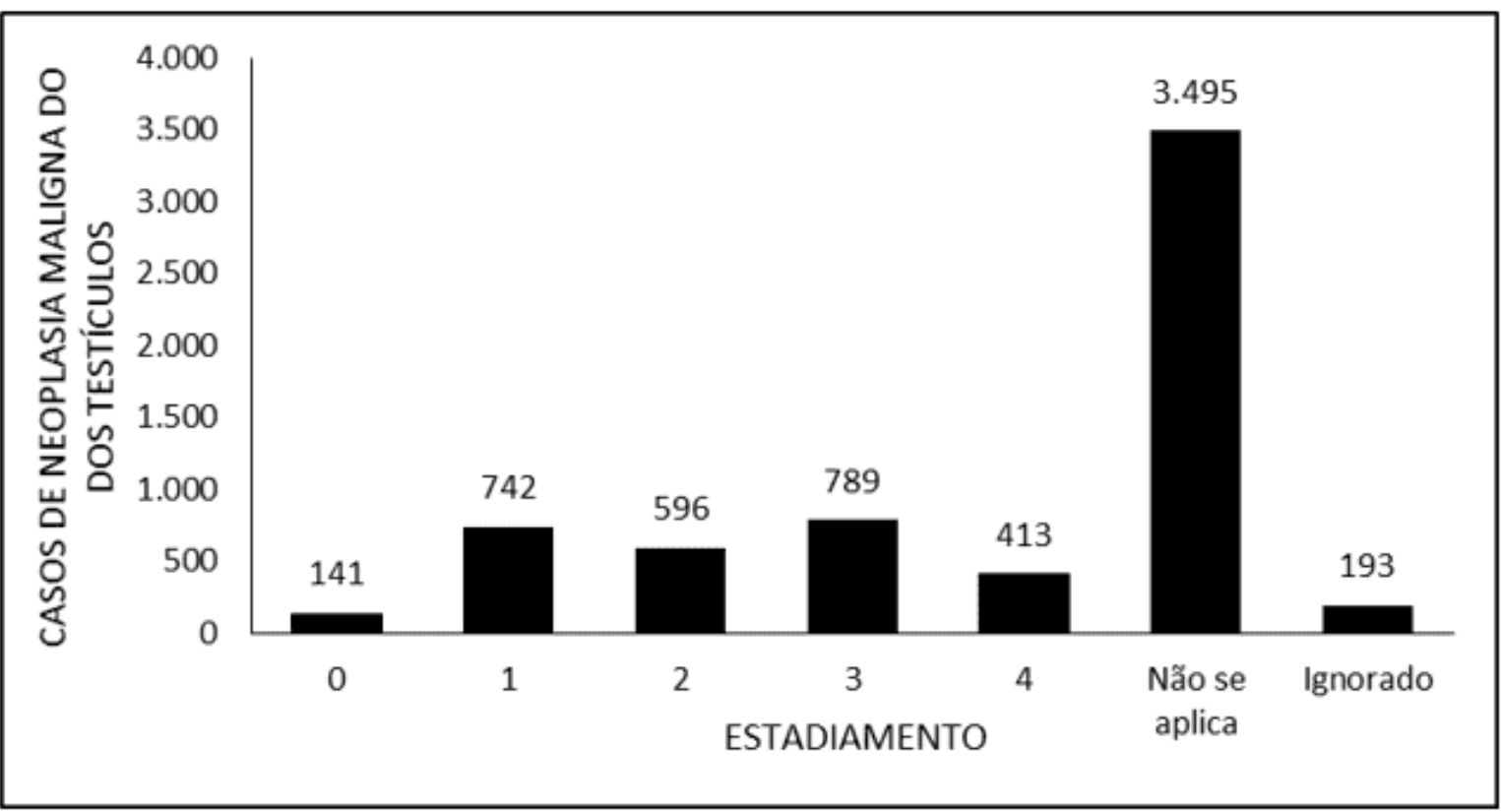

A Tabela 1 denota o número de casos de neoplasia maligna dos testículos no Brasil entre os anos de 2015 e 2019, mediante a faixa-etária. Nota-se que as 5 faixas de idade com o maior número de casos notificados de neoplasia maligna testicular são: 25 a 29 anos (1.312), 30 a 34 anos (1.157), 20 a 24 anos (1.072), 35 a 39 anos (811) e 0 a 19 anos (563). Além disso, notou-se que o maior número de casos notificados ocorreu em 2019, com 1.841 casos.

RC: 99646

Disponível em: https://www.nucleodoconhecimento.com.br/saude/neoplasia 
Tabela 1 Mostra o número de casos de neoplasia maligna dos testículos no Brasil entre os anos de 2015 e 2019, mediante a faixa-etária.

\begin{tabular}{ccccccc}
\hline Faixa Etária & $\mathbf{2 0 1 5}$ & $\mathbf{2 0 1 6}$ & $\mathbf{2 0 1 7}$ & $\mathbf{2 0 1 8}$ & $\mathbf{2 0 1 9}$ & Total \\
\hline 0 a 19 anos & 81 & 91 & 91 & 125 & 175 & 563 \\
20 a 24 anos & 177 & 206 & 175 & 245 & 269 & 1.072 \\
25 a 29 anos & 225 & 222 & 223 & 315 & 327 & 1.312 \\
30 a 34 anos & 206 & 221 & 206 & 230 & 294 & 1.157 \\
35 a 39 anos & 120 & 121 & 143 & 192 & 235 & 811 \\
40 a 44 anos & 57 & 62 & 80 & 109 & 112 & 420 \\
45 a 49 anos & 33 & 50 & 33 & 68 & 78 & 262 \\
50 a 54 anos & 28 & 22 & 29 & 52 & 56 & 187 \\
55 a 59 anos & 15 & 8 & 15 & 35 & 59 & 132 \\
60 a 64 anos & 8 & 10 & 13 & 32 & 59 & 122 \\
65 a 69 anos & 7 & 8 & 5 & 39 & 51 & 110 \\
70 a 74 anos & 4 & 3 & 3 & 31 & 50 & 91 \\
75 a 79 anos & 4 & 1 & 0 & 19 & 42 & 66 \\
80 anos e mais & 1 & 2 & 2 & 25 & $\mathbf{1 . 8 4 1}$ & $\mathbf{6 . 3 6 9}$ \\
\hline Total & $\mathbf{9 6 6}$ & $\mathbf{1 . 0 2 7}$ & $\mathbf{1 . 0 1 8}$ & $\mathbf{1 . 5 1 7}$ & &
\end{tabular}

A Figura 2 abrange o número de casos de neoplasia maligna dos testículos no Brasil entre os anos de 2015 e 2019, mediante a modalidade terapêutica empregada. Nota-se que a maior parcela dos pacientes (3.495) foi tratada cirurgicamente, sendo que 2.594 foram tratados mediante o uso de quimioterapia. A radioterapia foi utilizada em 86 pacientes e apenas 1 paciente fez uso das três modalidades terapêuticas. Não houve informação sobre o tratamento empregado em 193 pacientes.

RC: 99646

Disponível em: https://www.nucleodoconhecimento.com.br/saude/neoplasia 
Figura 2 Mostra o número de casos de neoplasia maligna dos testículos no Brasil entre os anos de 2015 e 2019, mediante a modalidade terapêutica.

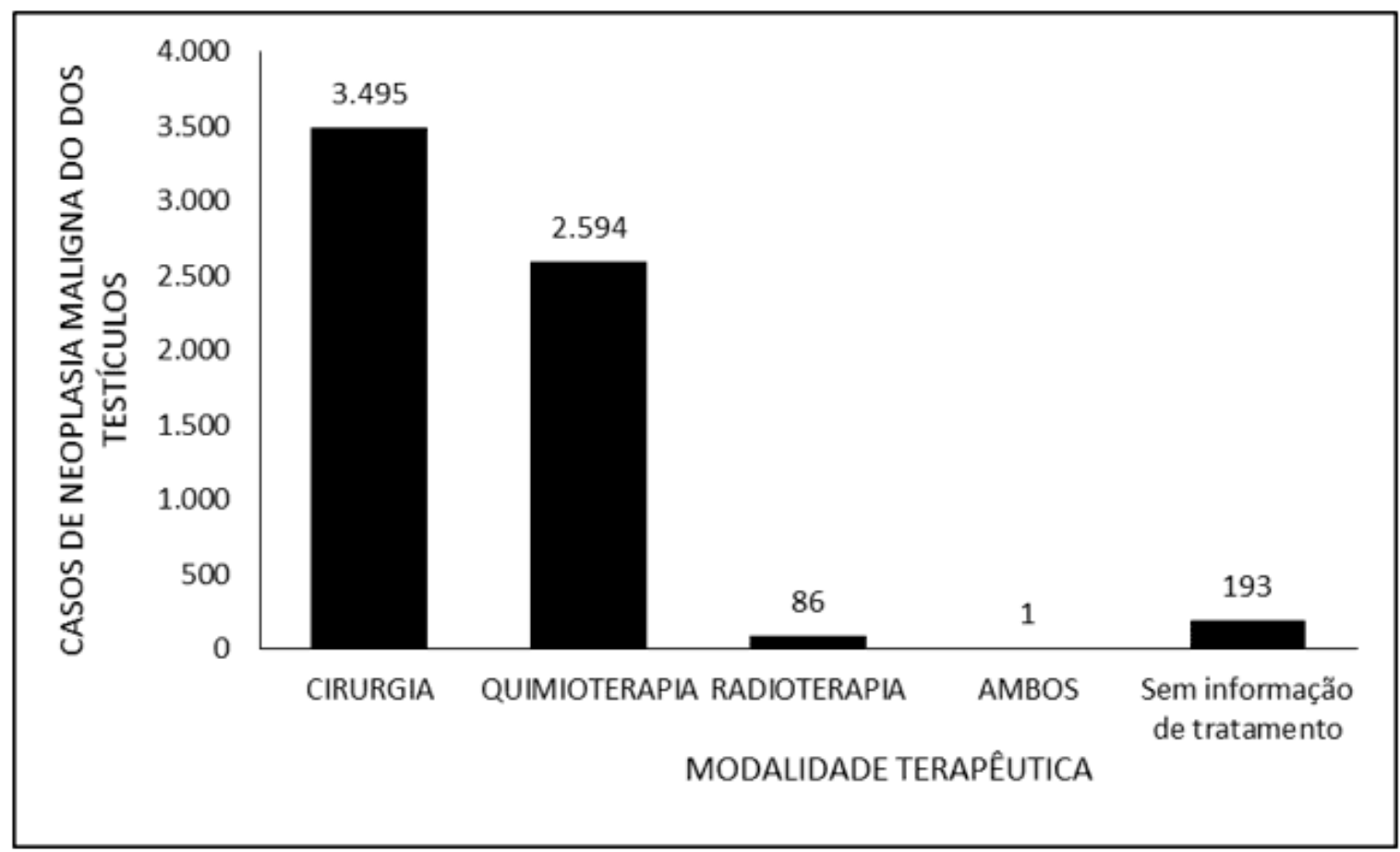

A Figura 3 denota o número de casos de neoplasia maligna dos testículos no Brasil entre os anos de 2015 e 2019, mediante o tempo de tratamento. A ampla maioria dos casos notificados refere-se ao tempo de tratamento de até 30 dias (4.216), seguido por mais de 60 dias (1.211) e 31 a 60 dias (749). Não houve informação sobre o tempo de tratamento para 193 pacientes.

RC: 99646

Disponível em: https://www.nucleodoconhecimento.com.br/saude/neoplasia 
Figura 3 Mostra o número de casos de neoplasia maligna dos testículos no Brasil entre os anos de 2015 e 2019, mediante o tempo de tratamento.

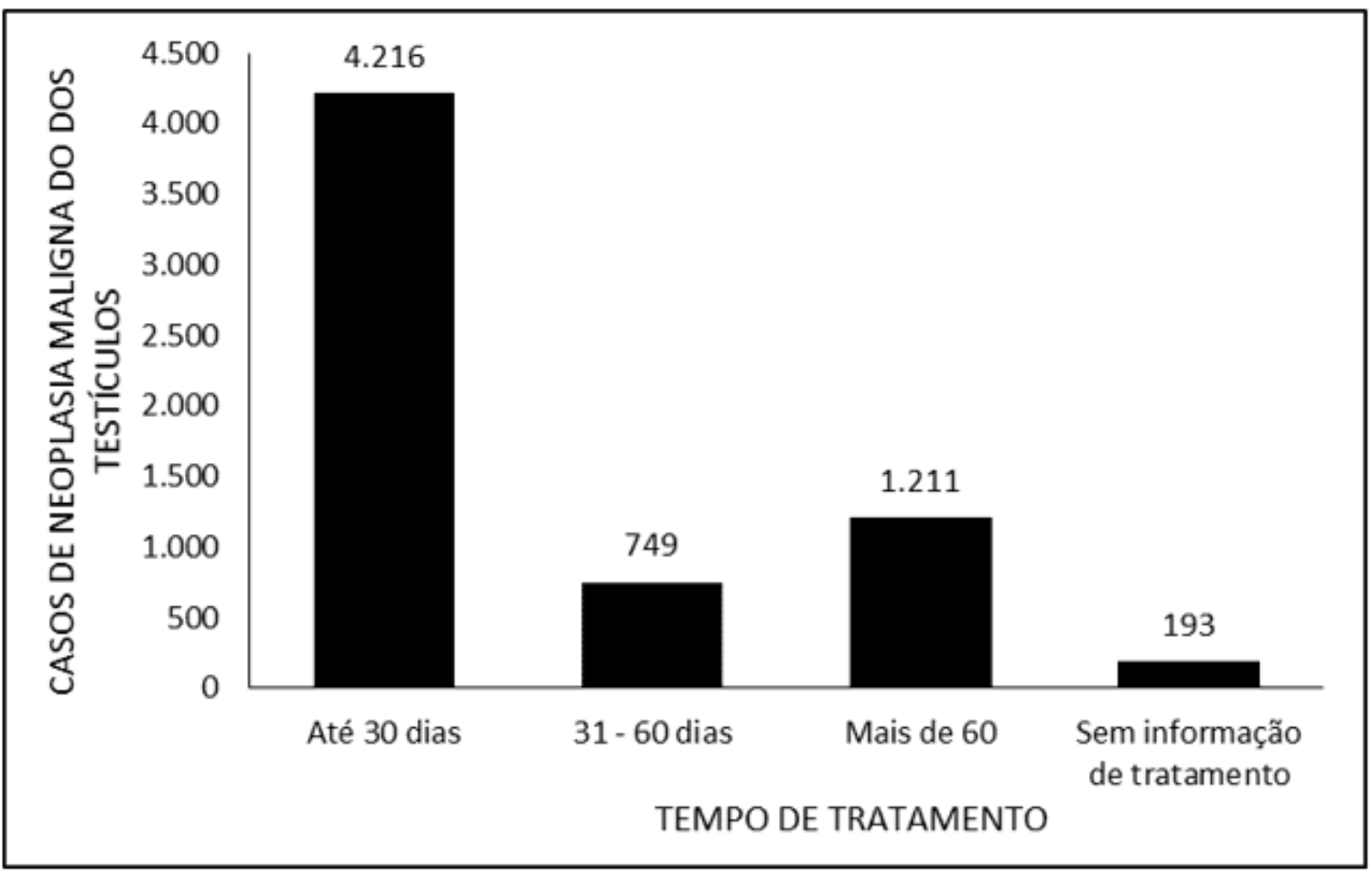

A Figura 4 denota o número de casos de neoplasia maligna dos testículos no Brasil entre os anos de 2015 e 2019, mediante a região de residência. A maioria dos casos refere-se à região Sudeste (2.785), seguida pelas regiões Sul (2.232), Nordeste (743), Centro-Oeste (374) e Norte (235).

RC: 99646

Disponível em: https://www.nucleodoconhecimento.com.br/saude/neoplasia 
Figura 4 Mostra o número de casos de neoplasia maligna dos testículos no Brasil entre os anos de 2015 e 2019, mediante a região da residência.

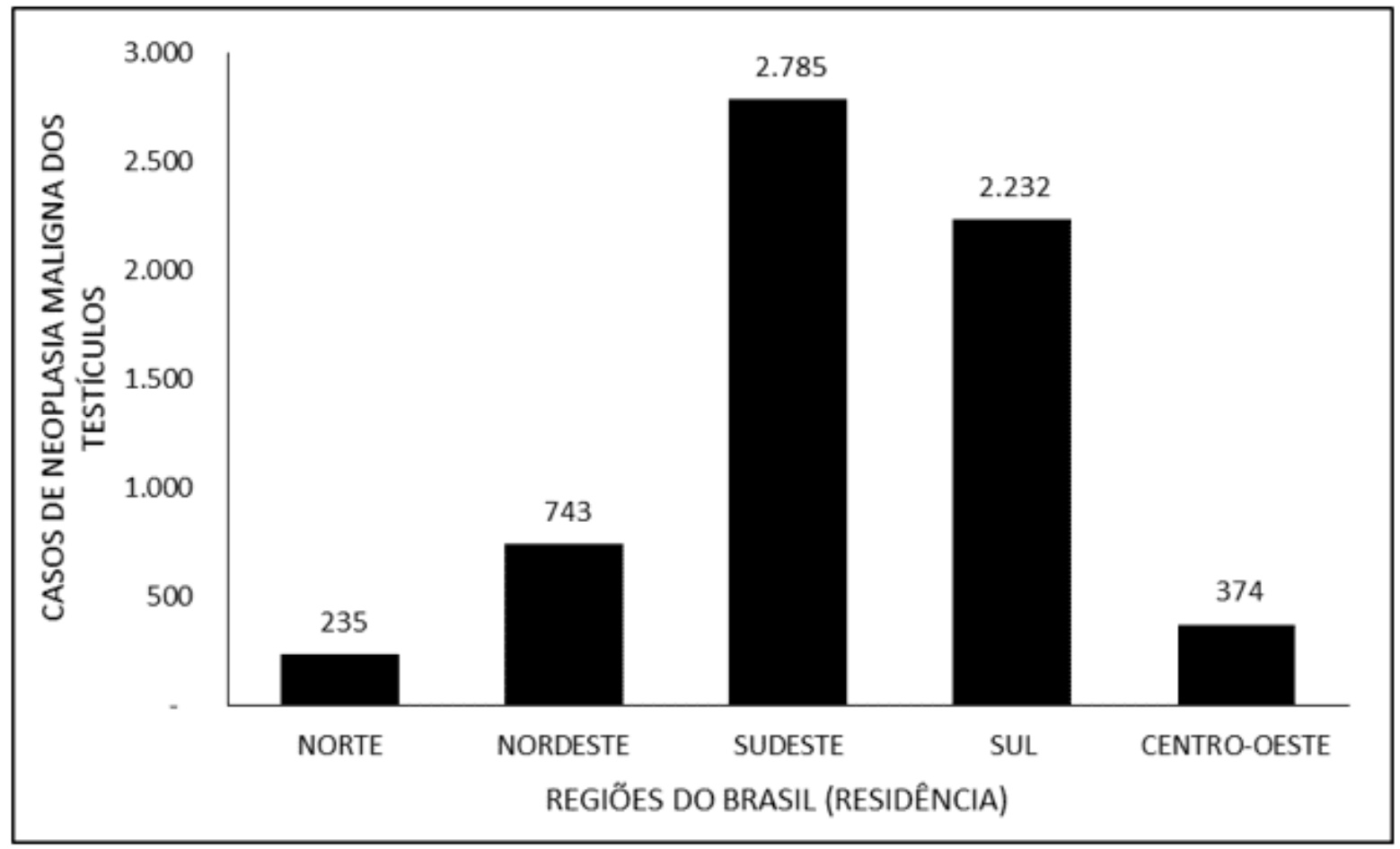

A Figura 5 denota o número de casos de neoplasia maligna dos testículos no Brasil entre os anos de 2015 e 2019, mediante a região do diagnóstico. Nota-se que a maior parcela dos diagnósticos ocorreu na região Sudeste (2.829), seguida pelas regiões Sul (2.245), Nordeste (731), Centro-Oeste (333) e Norte (231).

RC: 99646

Disponível em: https://www.nucleodoconhecimento.com.br/saude/neoplasia 
Figura 5 Mostra o número de casos de neoplasia maligna dos testículos no Brasil entre os anos de 2015 e 2019, mediante a região do diagnóstico.

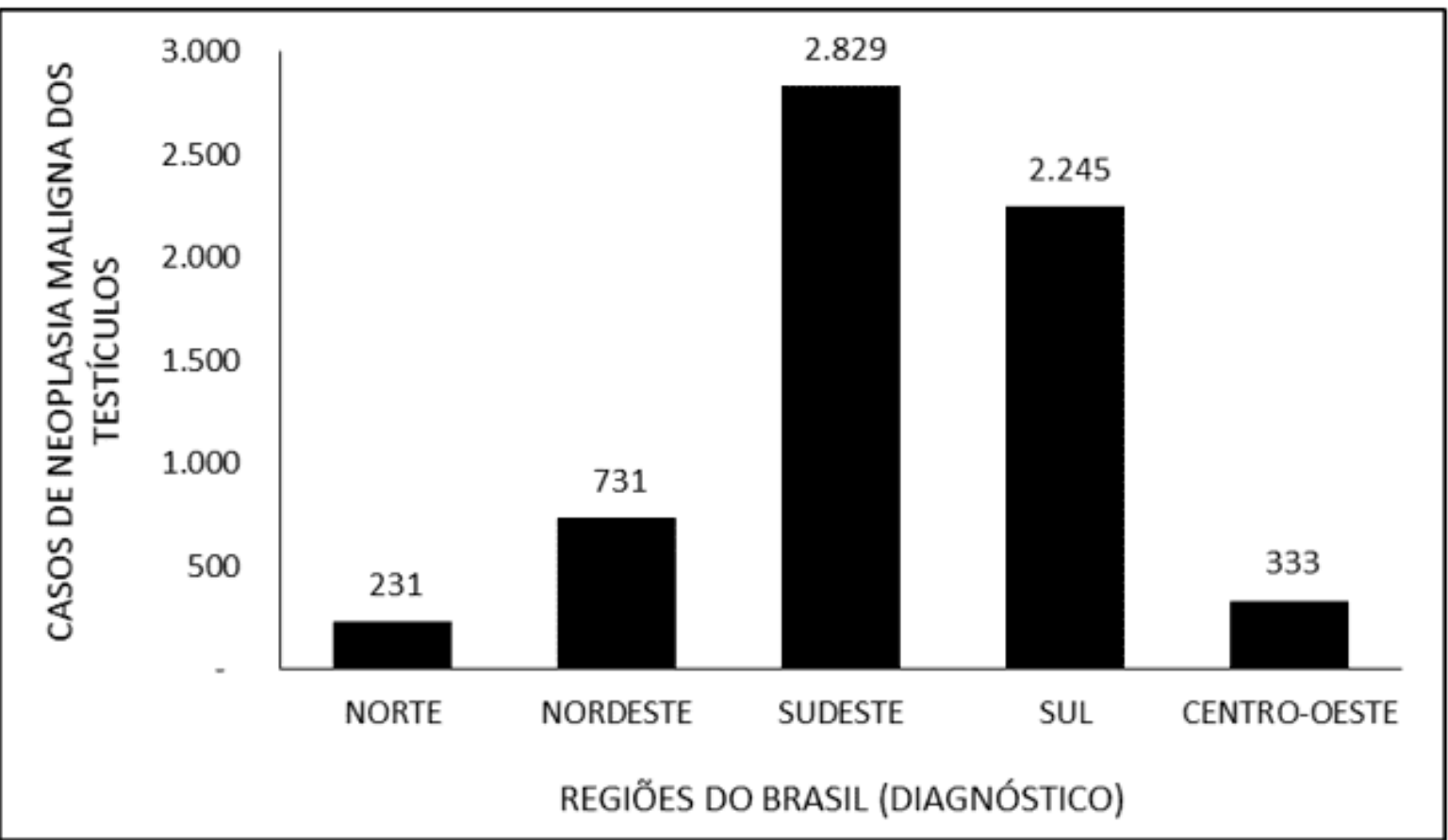

A Figura 6 abrange o número de casos de neoplasia maligna dos testículos no Brasil entre os anos de 2015 e 2019, mediante a região do tratamento. A maioria dos casos (2.859) foi notificada como "ignorado". A região Sudeste foi a que apresentou a maior notificação de tratamentos para neoplasia maligna testicular, com 2.731 notificações, seguida pelas regiões Sul (2.211), Nordeste (689), Centro-Oeste (327) e Norte (218).

RC: 99646

Disponível em: https://www.nucleodoconhecimento.com.br/saude/neoplasia 
Figura 6 Mostra o número de casos de neoplasia maligna dos testículos no Brasil entre os anos de 2015 e 2019, mediante a região do tratamento.

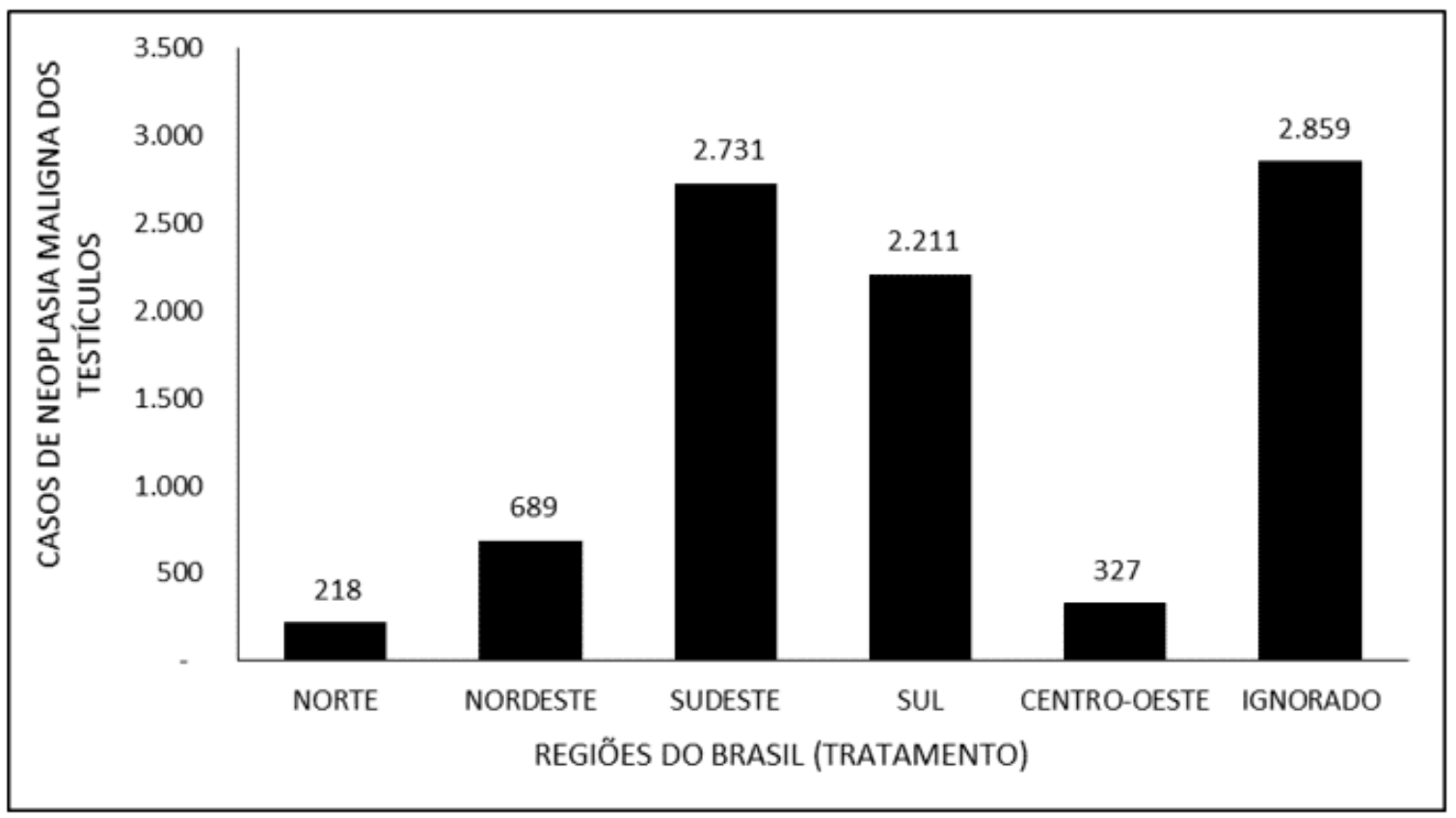

\section{DISCUSSÃO}

Como é possível observar na Tabela 1, houve crescente aumento do número de casos registrados de neoplasia maligna dos testículos no Brasil entre os anos de 2015 e 2019, acompanhando a tendência mundial que, durante décadas, vêm registrando aumento da taxa de incidência de câncer testicular em muitos países. No entanto, as razões para este fenômeno ainda são desconhecidas (Acs, 2021).

O alto número de diagnósticos de neoplasia maligna dos testículos no estádio 3 , pode ter fundamento na evolução silenciosa de uma massa sólida indolor, que muitas vezes é mal avaliada e diagnosticada como orquite ou epididimite, que acaba sendo tratada inadequadamente (de forma benigna), gerando um atraso na abordagem correta, que pode ser de até 20 semanas, possibilitando o surgimento de metástases (Moul, 2007; Shaw, 2008; Nery, 2019). Essas, por sua vez, apresentam RC: 99646

Disponível em: https://www.nucleodoconhecimento.com.br/saude/neoplasia 
sintomatologia clínica, permitindo assim o diagnóstico do processo neoplásico e metastático já presente, como sintomas respiratórios (dispneia, tosse e hemoptise) (Shaw, 2008).

Como já foi ilustrado em outros estudos, a faixa etária mais comum para desenvolver câncer testicular foi de 15 a 34 anos, corroborando assim, para os dados apresentados nessa pesquisa (Baird et al., 2018). Além disso, fatores que podem ter levado a detecção da neoplasia nessa faixa etária podem ser a sexarca precoce e vida sexual ativa, as quais possibilitam maior autoconhecimento corporal e múltiplos parceiros sexuais, o que permite notar mais precocemente a formação de um edema escrotal de causa desconhecida e consequente busca por atendimento médico (Adra e Einhorn, 2017). Importante citar que o rastreamento do câncer de testículo não é recomendado, uma vez que há evidências de que sua prática traga mais benefícios do que riscos (Inca, 2021).

O procedimento cirúrgico foi estabelecido como tratamento padrão-ouro, pois retira o foco neoplásico desde cordão espermático até nível do anel inguinal inferior, poupando manipulação excessiva da cadeia linfonodal e do próprio foco neoplásico, para, assim, evitar extravasamento celular do processo canceroso (Krege et al., 2008; Rajpert-De-Meyts et al., 2016; Ghoreifi e Djaladat, 2019; Eau, 2021).

Uma justificativa para o tratamento com tripla modalidade é a presença de metástase a distância, o que faz necessário utilizar quimioterapia e radioterapia juntamente com o procedimento cirúrgico, aumentando a sobrevida para 96\% em 10 anos (Nery, 2019; Nci, 2021), variando as combinações e ciclos de quimioradioterapia de acordo com o estádio clínico e variáveis individuais, como por exemplo 4 ciclos de BEP (Cisplatina $20 \mathrm{mg} / \mathrm{m}^{2}$, endovenoso no dia 1 a dia 5; Etoposideo $100 \mathrm{mg} / \mathrm{m}^{2}$, endovenoso no dia 1 a dia 5; Bleomicina $30 \mathrm{Ul}$ endovenoso nos dias 2, dia 9 e dia 16; Repetir a cada 21 dias) (Nery, 2019). 
Entende-se que, muitas vezes, durante o processo diagnóstico confirmatório, optase pela orquiectomia inguinal, a qual é tida como procedimento terapêutico, já que remove o foco primário de neoplasia (Ghoreifi e Djaladat, 2019). Somado a isso, temos que no momento da formulação de hipótese diagnóstica com os exames radiológicos e escolha pela orquiectomia radical até nível do anel inguinal inferior, e substituição por prótese se faz necessário investigar o risco cirúrgico e se há focos metastáticos em outras regiões por meio dos marcadores tumorais. (Krege et al., 2008; Robinson et al., 2015; Ghoreifi e Djaladat, 2019; Gilligan et al., 2019).

Considerando-se que $49,5 \%$ dos hospitais habilitados para o manejo de processos neoplásicos estão localizados na região Sudeste do país, seguido da região Sul, com $24,2 \%$, e que ambas são possuem maiores disponibilidades de unidades de reconhecimento, é possível inferir que também possuem um melhor sistema para reconhecimento diagnóstico desta neoplasia. Além disso, os maiores índices de tratamento situam-se nas regiões Sul e Sudeste do Brasil, sendo 37,9\% do total destes diagnósticos registrados só no estado de São Paulo (Inca, 2019a; 2019b; 2019c; 2019d; 2019e; 2019f; 2019g; 2019h).

O câncer de testículo é uma neoplasia maligna que atinge um número considerável de adultos jovens com vida sexual ativa e que pode levar à morte (Park et al., 2018). Porém, representa uma das neoplasias malignas mais curáveis quando identificado prontamente e tratado com uma abordagem multimodal. Com o manejo eficaz, o prognóstico é excelente, com taxa de cura> $90 \%$ e taxa de sobrevida em cinco anos> 95\% (Smith et al., 2018).

\section{CONCLUSÃO}

A partir das informações reveladas nesta pesquisa, é possível observar um crescente aumento do diagnóstico de neoplasia maligna dos testículos no Brasil, com quase o dobro do número de casos observados entre os anos de 2015 e 2019.

RC: 99646

Disponível em: https://www.nucleodoconhecimento.com.br/saude/neoplasia 
Apesar de relativamente incomum, o câncer de testículo é potencialmente mortal e sua gravidade não deve ser subestimada, devendo ser diagnosticado e tratado o mais precocemente possível. Possui elevada chance de cura, com tratamento cirúrgico definitivo, após diagnóstico confirmatório, na maioria dos casos, permitindo ao indivíduo acometido ter uma vida normal. Assim, mais estudos são necessários para revelar as razões do aumento de casos de câncer de testículo no Brasil e no mundo, para entender se as diferenças regionais estão relacionadas ao número de casos ou se é falha no diagnóstico e registro, bem como servirem de base para ações do poder público, no sentido de planejar e executar políticas dirigidas ao combate dos fatores desencadeantes dessa doença.

\section{REFERÊNCIAS}

ACS. Key Statistics for Testicular Cancer. New York NY, 2021. Disponível em: < https://www.cancer.org/cancer/testicular-cancer/about/key-statistics.html\#references >. Acesso em: 05 mar 2021.

ADRA, N.; EINHORN, L. H. Testicular Cancer Update. Clinical Advances in Hematology \& Oncology, v. 15, n. 5, p. 386-396, 2017.

BAIRD, D. C.; MEYERES, G.; HU, J. S. Testicular Cancer: Diagnosis and Treatment. American Family Physician, v. 97, n. 4, p. 261-268, 2018.

CHAN, E.; WAYNE, C.; NASR, A. Ideal timing of orchiopexy: a systematic review. Pediatric Surgery International, v. 30, n. 1, p. 87-97, 2014.

CHENG, L. et al. Testicular cancer. Nature Reviews Disease Primers, v. 4, n. 29, p. 1-24, 2018. 
COOK, M. B. et al. Systematic review and meta-analysis of perinatal variables in relation to the risk of testicular cancer-experiences of the son. International Journal of Epidemiology, v. 39, n. 6, p. 1605-1618, 2010.

DIAS, A. D. A. et al. Update on the Main Aspects Related to Breast Cancer. Revista Científica Multidisciplinar Núcleo do Conhecimento, v. 4, p. 5-17, 2017. Disponível em: < https://www.nucleodoconhecimento.com.br/health/breast-cancer >.

DIECKMANN, K. P.; FREY; LOCK, G. Contemporary diagnostic work-up of testicular germ cell tumours. Nat Rev Urol v. 10, p. 703-712, 2013.

EAU. Testicular Cancer. Düsseldorf DE, 2021. Disponível em: < https://uroweb.org/guideline/testicular-cancer/\#1 >. Acesso em: 06 mar 2021.

FACCO, L. et al. Neoplasia maligna de esôfago: uma análise epidemiológica dos casos notificados no Brasil entre 2015 e 2019. Research, Society and Development, v. 10, n. 2, p. 1-14, 2021. Disponível em: < https://rsdjournal.org/index.php/rsd/article/view/12750/11622 >.

FITZMAURICE, C. et al. Global, Regional, and National Cancer Incidence, Mortality, Years of Life Lost, Years Lived With Disability, and Disability-Adjusted Life-years for 32 Cancer Groups, 1990 to 2015: A Systematic Analysis for the Global Burden of Disease Study. .JAMA Oncol, v. 3, n. 4, p. 524-548, 2017.

GHAZARIAN, A. A. et al. Recent trends in the incidence of testicular germ cell tumors in the United States. Andrology, v. 3, n. 1, p. 13-18, 2014.

GHOREIFI, A.; DJALADAT, H. Management of Primary Testicular Tumor. Urologic Clinics of North America, v. 46, n. 3, p. 333-339, 2019. 
GILLIGAN, T. et al. Testicular Cancer, Version 2.2020, NCCN Clinical Practice Guidelines in Oncology. Journal of the National Comprehensive Cancer Network, v. 17, n. 12, p. 1529-1554, 2019.

HEMMINKI, K.; LI, X. Familial risk in testicular cancer as a clue to a heritable and environmental aetiology. British Journal of Cancer, v. 90, n. 9, p. 1765-1770, 2004.

INCA. Onde tratar pelo SUS. Brasília DF, 2019a. Disponível em: < https://www.inca.gov.br/onde-tratar-pelo-

sus\#: :text=Existem\%20atualmente\%20317\%20unidades\%20e,exame\%20até\%20ci rurgias\%20mais\%20complexas >. Acesso em: 06 mar 2021.

Paraná. Brasília DF, 2019b. Disponível em: < https://www.inca.gov.br/onde-tratar-pelo-sus/parana >. Acesso em: 06 mar 2021.

Santa Catarina. Brasília DF, 2019c. Disponível em: < https://www.inca.gov.br/onde-tratar-pelo-sus/santa-catarina >.

- Rio Grande do Sul. Brasília DF, 2019d. Disponível em: < https://www.inca.gov.br/onde-tratar-pelo-sus/rio-grande-sul >. Acesso em: 06 mar 2021.

Minas Gerais. Brasília DF, 2019e. Disponível em: < https://www.inca.gov.br/onde-tratar-pelo-sus/minas-gerais >. Acesso em: 12 jan 2021.

São Paulo. Brasília DF, 2019f. Disponível em: < https://www.inca.gov.br/onde-tratar-pelo-sus/sao-paulo >. Acesso em: 15 jan 2021.

Rio de Janeiro. Brasília DF, 2019g. Disponível em: < https://www.inca.gov.br/onde-tratar-pelo-sus/rio-janeiro >. Acesso em: 15 jan 2021. RC: 99646

Disponível em: https://www.nucleodoconhecimento.com.br/saude/neoplasia 
Espírito Santo. Brasília DF, 2019h. Disponível em: < https://www.inca.gov.br/onde-tratar-pelo-sus/espirito-santo >. Acesso em: 01 jul 2021.

- Câncer de testículo. Brasilia DF, 2021. Disponível em: < https://www.inca.gov.br/tipos-de-cancer/cancer-de-testiculo >. Acesso em: 06 mar 2021.

KIER, M. G. et al. Second Malignant Neoplasms and Cause of Death in Patients With Germ Cell Cancer. JAMA Oncology, v. 2, n. 12, p. 1624-1627, 2016.

KREGE, S. et al. European consensus conference on diagnosis and treatment of germ cell cancer: a report of the second meeting of the European Germ Cell Cancer Consensus group (EGCCCG): part I. Eur Urol v. 53, n. 3, p. 478-496, 2008.

LIP, S. Z. L. et al. A meta-analysis of the risk of boys with isolated cryptorchidism developing testicular cancer in later life. Archives of Disease in Childhood, v. 98, n. 1, p. 20-26, 2012.

MOUL, J. W. Diagnosis of Testicular Cancer. Urologic Clinics of North America, v. 34, n. 2, p. 109-117, 2007.

NCl. Cancer Stat Facts: Testicular Cancer. USA, 2021. Disponível em: < https://seer.cancer.gov/statfacts/html/testis.html >. Acesso em: 03 mar 2021.

NERY, R. C. Câncer de Testículo. In: SANTOS, M. (Ed.). Diretrizes oncológicas 2. São Paulo SP: Doctor Press Ed. Científica, 2019.

PARK, J. S. et al. Recent global trends in testicular cancer incidence and mortality. Medicine, v. 97, n. 37, p. 1-7, 2018. Disponível em: < https://www.ncbi.nlm.nih.gov/pmc/articles/PMC6155960 >. 
PIERORAZIO, P. M. et al. Non-risk-adapted Surveillance for Stage I Testicular Cancer: Critical Review and Summary. European Urology, v. 73, n. 6, p. 899-907, 2018.

RAJPERT-DE-MEYTS, E. et al. Testicular germ cell tumours. The Lancet, v. 387, n. 10029, p. 1762-1774, 2016.

ROBINSON, $R$. et al. Is it safe to insert a testicular prosthesis at the time of radical orchidectomy for testis cancer: an audit of 904 men undergoing radical orchidectomy. BJU International, v. 117, n. 2, 2015.

ROSEN, A. et al. Global Trends in Testicular Cancer Incidence and Mortality. European Urology, v. 60, n. 2, p. 374-379, 2011.

SHAW, J. Diagnosis and Treatment of Testicular Cancer. American Family Physician, v. 7, n. 4, p. 469-474, 2008.

SMITH, Z. L.; WERNTZ, R. P.; EGGENER, S. E. Testicular Cancer: Epidemiology, Diagnosis, and Management. Medical Clinics of North America, v. 102, n. 2, p. 251-264, 2018. Disponível em: https://www.sciencedirect.com/science/article/abs/pii/S0025712517301578?via\%3Di hub $>$.

WALSH, T. J. et al. Prepubertal Orchiopexy for Cryptorchidism May be Associated With Lower Risk of Testicular Cancer. The Journal of Urology, v. 178, n. 4, p. 1440-1446, 2007.

Enviado: Outubro, 2021.

Aprovado: Outubro, 2021. 